\title{
A new method to monitor drugs at dance venues
}

\author{
John D Ramsey, Marcus A Butcher, Martin F Murphy, Terry Lee, Atholl Johnston, David W Holt
}

Information on the use of illicit drugs depends heavily on users' recall-what they remember, or think, that they have purchased-and on seizures by law enforcement agencies. Neither method may be able to give accurate information on what is currently available. ${ }^{1}$ We have developed a new method designed to gain information on current drug consumption in a London dance venue.

\section{Methods and results}

We analysed solid dose formulations retrieved from an amnesty bin at a London dance venue, into which visitors were required to discard illicit drugs and into which security staff place substances found during searches. We obtained a Home Office licence to analyse the contents of the bin, which were removed in the presence of a police officer and sealed in evidence bags. The data reported are for one year up to February 1999.

The 299 items, which ranged from single tablets to bags containing several, comprised 156 tablets and 90 blocks of resin); 11 capsules; 10 knives; 5 "snorters" (often, but not exclusively, used to take cocaine or amphetamine); and 1 CS gas canister.

Initially, we tried to identify solid dose formulations using the TICTAC database (an identification CD Rom for tablets and capsules). ${ }^{2}$ We confirmed or established identification using a simple chemical test, the Marquis reagent $^{3}$ and gas chromatography with masswith many of the drugs used in dance venues, including 3,4-methylenedioxymethylamphetamine (MDMA, known as ecstasy) and several related compounds, producing various colour reactions.

The table shows the drugs detected in the 105 (67\%) tablets and the $79(88 \%)$ powder items that could be identified. A high proportion of the tablets contained MDMA, whereas the powders were predominantly amphetamine. Two formulations of MDMA were not known to the Forensic Science Service, and 16 formulations were not noted in TICTAC. Of concern clinically was the presence of 4-methylthioamphetamine (4-MTA, known as flatliners) in nine tablets. This drug is known to be highly toxic, having been implicated in four deaths in Britain and one in the Netherlands (see www.londontox.org.uk) and does not give a colour reaction with the Marquis reagent. Although there were 17 seizures of 4-MTA in England during 1997-8, the drug was not thought to have been on the streets after late 1998. Our data show, however, that it was still in circulation during 1999.

The table also shows that several "prescription only" and "over the counter" medicines were also found, together with some items of confectionery, such as Smints. Some of these substances could have been used fraudulently to mimic illicit drugs, a distinct possibility in the case of paracetamol, which was found powdered and in wraps. It is likely that many of the capsules were food supplements, usually a cocktail of amino powders; 26 cannabis items (joints, herbal material, or spectrometry detection. The Marquis reagent reacts
Drugs found in 156 tablets and 90 powders retrieved from amnesty bin in London dance venue for one year up to February 1999. Values are percentages (numbers) of items

\begin{tabular}{lcc} 
Compound & Tablets & Powders* \\
\hline Unidentified & $33(51)$ & $12(11)$ \\
\hline MDMA ("ecstasy") & $29(46)$ & $6(5)$ \\
\hline MDEA & $2(3)$ & 0 \\
\hline 4-MTA ("flatliners") & $1(2)$ & 0 \\
\hline Amphetamine & $3(5)$ & $47(42)$ \\
\hline Cocaine & 0 & $8(7)$ \\
\hline Ketamine & $4(6)$ & $4(4)$ \\
\hline Ephedrine & $2(3)$ & 0 \\
\hline Caffeine & $3(5)$ & $31(28)$ \\
\hline Paracetamol & $6(9)$ & $9(8)$ \\
\hline Other "over the counter" medication† & $8(12)$ & $4(4)$ \\
\hline Other "prescription only" medication $\ddagger$ & $6(9)$ & $1(1)$ \\
\hline Confectionery & $4(6)$ & 0 \\
\hline
\end{tabular}

MDEA=methylenedioxyethamphetamine. *Values total $>100$ as some preparations contained more than one active ingredient.

tIncluded diphenhydramine and salicylate.

łIncluded phenytoin, carbamazepine, doxylamine, promethazine, and diazepam.

acids and vitamins, taken before ingesting ecstasy (a practice known as preloading).

\section{Comment}

In the era of evidence based medicine this method of monitoring drugs in dance venues does not rely on what the user thinks he or she has bought. If the contents of the bins were analysed regularly the results would reflect what is currently available on the streets. This would allow timely information to be disseminated on the appearance of new drugs or formulations, through the TICTAC database and its associated secure website. Accurate information on drug use would allow healthcare professionals to formulate better advice on avoiding injury through drug use and to design the most appropriate campaigns against drug use. ${ }^{4}$

Other clubs are willing to participate in a study of this nature, and our approach also has the benefit of encouraging a healthy cooperation between the police, clubs, researchers, and drug users.

We gratefully acknowledge the collaboration of the Metropolitan Police (Southwark) in London.

Contributors: JDR conceived and designed the study and contributed to the final manuscript. MAB helped in the analysis and prepared the first draft of the manuscript. MFM helped in the identification of the solid dose formulations and contributed to the final documentation of the results. TL developed the mass-spectrometry methodology, helped in the interpretation of data, and contributed to the manuscript. AJ helped in the data analysis and contributed to the manuscript. DWH was involved in the development of the study, the logistics of organising the analyses, and wrote the final manuscript.

Funding: None.

Competing interests: None declared.

1 Ramsey JD, Johnston A, Holt DW. Death rate from use of ecstasy or heroin [letter]. Lancet 1999;354:2166.

2 Ramsey JD, ed. TICTAC, version 4.4. Norwich: Stationery Office, 1999.

3 Moffat AC, ed. Clarke's isolation and identification of drugs. 2nd ed. London: Moffat AC, ed. Clarke's isolation and
Pharmaceutical Press, 1986:139.

4 Sherlock K, Wolff K, Hay AW, Conner M. Analysis of illicit ecstasy tablets: implications for clinical management in the accident and emergency department. J Accid Emerg Med 1999;16:194-7.

(Accepted 11 July 2001)
St George's

Hospital Medical

School, London SW17 0RE

John D Ramsey

head, toxicology unit

Marcus A Butcher

toxicology service

manager

Terry Lee

senior clinical scientist

David W Holt

director, analytical

unit

King's College,

London SE1 8WA

Martin F Murphy

student

St Bartholomew's

and the Royal

London School of

Medicine and

Dentistry, London

EC1M 6BQ

Atholl Johnston

head, laboratory

services

Correspondence to:

D W Holt

d.holt@sghms.ac.uk

BMJ 2001;323:603 